\title{
Las sirenas como arquetipos transculturales y como recurso para la educación literaria
}

\author{
Aitana MARTOS GARCÍA \\ Departamento de Educación \\ Universidad de Almería \\ aitmartos@gmail.com
}

Recibido: 13 de marzo de 2016

Aceptado: 13 de junio de 2016

\section{RESUMEN}

A partir de un análisis mitográfico y comparatista, se examinan las distintas representaciones de las sirenas como arquetipos transculturales y los mecanismos que han ido marcando la evolución de su prosopografía, subrayando la importación de los dialogismos y la hibridación. A partir de estas iconologías, se exponen algunos criterios e itinerarios posibles para armar propuestas de intervención didáctica, con énfasis en la crítica feminista. La conclusión es que las múltiples representaciones de sirenas son un ejemplo de "narrativas móviles", en tanto que han sido fruto de influencias culturales, préstamos y transculturaciones de diversa índole. Por tanto, la tradición de sirena se configura como un palimpsesto de identidades susceptibles de ser aprovechadas para la educación literaria de los alumnos.

Palabras clave: sirenas, prosopografía, transculturación, feminismo, criollización, mitos, leyendas, dialogismo, hibridación

Sirens as cross-cultural archetypes and as a resource for literary education

\begin{abstract}
Based on a comparative analysis and mythographic, we examine the different representations of sirens as cross-cultural archetypes and mechanisms that have marked the evolution of its prosopography, underlining the importation of dialogism. From these iconologies, some criteria and possible itineraries are set to put together proposals for educational intervention, with emphasis on feminist criticism. The conclusion is that multiple representations of mermaids are an example of "mobile narratives", while fruits have been subjected to cultural influences, loans and transculturations of various kinds. Therefore, tradition siren is configured as a palimpsest of identities that can be exploited for literary education.
\end{abstract}

Key words: mermaids, prosopography, transculturation, feminism, creolization, myths, legends, dialogism, hybridization 


\section{Les Sirènes comme des archétypes interculturels et comme une ressource} pour l'éducation littéraire

\section{RÉSUMÉ}

D'après une analyse mythographique et comparative, on examine les différentes représentations des sirènes comme des archétypes et des mécanismes qui ont marqué l'évolution de son prosopographie interculturelle, soulignant l'importation des dialogismes et l'hybridation. Ces iconologies, certains critères et les itinéraires possibles sont des pistes pour des propositions d'intervention éducative, en mettant l'accent sur la critique féministe. La conclusion est que de multiples représentations de sirènes sont un exemple de «récits mobiles», soumis à des influences culturelles, aux prêts et aux transculturations de divers types. Par conséquent, la tradition de la sirène est configurée comme un palimpseste d'identités qui peuvent être exploitées pour l'éducation littéraire.

Mots-clés: Sirènes, prosopographie, transculturation, féminisme, créolisation, mythes, légendes, dialogisme, hybridation

SUMARIO: 1. Introducción: la sirena como arquetipo transcultural; 2. Tipología de la sirena; 3. La sirena como palimpsesto; 4. Algunos posibles itinerarios didácticos; 5. Guía de lectura intertextual a partir de las leyendas de la sirena Parténope y de "ojos verdes" de Bécquer; 6. Conclusiones; 7. Bibliografía.

En el pueblo de Itaca hay un puerto, el de Forcis, el viejo del mar, y en él hay dos salientes escarpados que se inclinan hacia el puerto y que dejan fuera el oleaje producido por silbantes vientos; dentro, las naves de buenos bancos permanecen sin amarras cuando llegan al término del fondeadero. Al extremo del puerto hay un olivo de anchas hojas y cerca de éste una gruta sombría y amable consagrada a las ninfas que llaman Náyades. Hay dentro cráteras y ánforas de piedra y también dentro fabrican las abejas sus panales. Hay dentro grandes telares de piedra donde las ninfas tejen sus túnicas con púrpura marina, juna maravilla para velas!, y también dentro corren las aguas sin cesar. Tiene dos puertas, la una del lado de Bóreas accesible a los hombres; la otra, del lado de Noto, es en cambio sólo para dioses y no entran por ella los hombres, que es camino de inmortales

(La Odisea, canto XIII) 


\title{
1608 \\ Puerto Príncipe \\ Silvestre de Balboa
}

En la casa de barro y palma de Silvestre de Balboa, escribano del cabildo de Puerto Príncipe, nace el primer poema épico de la historia de Cuba. Dedica el autor sus octavas reales al obispo Altamirano, que hace cuatro años fue secuestrado por el pirata francés Gilbert Giron en el puerto de Manzanillo. Al navío del pirata ascendieron, desde el reino de Neptuno, focas y nereidas condolidas del obispo, que no quiso en su defensa aceptar nada. Consiguieron los vecinos de Manzanillo reunir doscientos ducados, mil cueros y otras vituallas y por fin el corsario luterano soltó su presa. Desde los bosques llegaron a la playa, para dar la bienvenida al obispo rescatado, sátiros, faunos y semicapros que le trajeron guanábanas y otras delicias. Vinieron de los prados las napeas, cargadas de mameyes, piñas, tunas, aguacates, tabaco; $y$ vistiendo enaguas las dríades bajaron de los árboles, plenos los brazos de silvestres pitajayas y frutos del árbol birijí y de la alta jagua. También recibió el obispo Altamirano guabinas, dajaos y otros peces de río de manos de las náyades; y las ninfas de las fuentes y los estanques le regalaron unas sabrosas tortugas jicoteas de Masabo. Cuando se disponían los piratas a cobrar el rescate, cayeron sobre ellos unos pocos mancebos, flor y nata de Manzanillo, que valientemente les dieron su merecido. Fue un negro esclavo, llamado Salvador, quien atravesó con su lanza el pecho del pirata Gilbert Giron:

\author{
¡Oh Salvador criollo, negro honrado! \\ Vuele tu fama y nunca se consuma; \\ que en alabanza de tan buen soldado \\ es bien que no se cansen lengua y pluma.
}

Henchido de admiración y espanto, Silvestre de Balboa invoca a Troya y compara con Aquiles y Ulises a los vecinos de Manzanillo, después de haberlos mezclado con ninfas, faunos y centauros. Pero entre las portentosas deidades se han abierto paso, humildemente, las gentes de este pueblo, un negro esclavo que se portó como un héroe y muchas frutas, hierbas y animales de esta isla que el autor llama y ama por sus nombres

(Eduardo Galeano, Memorias del Fuego, Vol. I, Los nacimientos)

\section{INTRODUCCIÓN: LA SIRENA COMO ARQUETIPO TRANSCULTURAL}

La mitología comparada nos da amplias muestras del carácter heterogéneo de representaciones tan extendidas como las de las sirenas, que están siempre ligadas a genios o espíritus del agua (water spirit). Las representaciones, por ejemplo, de los ríos como serpientes, por la sinuosidad de sus cauces, o como toros, por el rugido de sus aguas en las inundaciones, es la misma que vincula las sirenas a las rocas escarpadas o acantilados de las costas que atraían y hacían perecer a la vez a navegantes con poca pericia, lo cual es relevante dada la importancia que tenía la navegación de cabotaje en la Antigüedad. 
Debemos a Carlos García Gual (2014) un amplio repaso a la figura de la sirena desde la mitografía clásica a la actualidad. Esta visión comparatista se completaría con otras, como la proveniente de los estudios culturales. Sería el caso de Edouard Glissant (1995), que ha trabajado sobre temas de criollización y define la noción de "poética de lo diverso".

Precisamente, el "traspaso" por así decir de estas tradiciones de origen europeo a América, desde la época de la colonia, originó diversos ejemplos de criollizacion y de transculturación, como es el caso de la propia Virgen de Guadalupe, pero que, en el caso que nos ocupa, se resume en la adaptación de las figuras clásicas a la hora de reconocer y aculturar mitos prehispánicos, de ahí que se hable de por parte de los propios americanos de ninfas o sirenas andinas (Millones y Tomoeda, 2011). Mecanismos que por lo demás son recreados por diversos autores, baste citar a Eduardo Galeano en Memorias del Fuego (1982). Todo lo cual nos revela la importancia del mestizaje no como una suma o "amalgamamiento" de materiales sino como alumbramiento de una realidad nueva, que no es ya algo sumativo sino fruto de un paisaje cultural nuevo que se enriquece de formas heredadas de percibir, catalogar y nombrar una realidad, en este caso deudoras de mitos clásicos.

El criollismo (Glissant, 1995) llega a configurar esta síntesis renovadora entre herencias culturales europeas, americanas y africanas, de tal modo que mestizaje, transculturación e hibridación se convierten en los mecanismos que dan vida a esta polifonía y dialogismo textual (Bajtin, 1974), que tienen además como fondo las propias culturas indígenas o prehispánicas. Toda esta negociación de identidades" explica lo que se ha dado en llamar la poética de lo diverso.

Situación que, por añadidura, tampoco es exclusiva de la (pos)modernidad, pues, como señala Ibáñez $(2014,160)$ ya los griegos importaron de Oriente la prosopografía de muchos de sus monstruos y potenciaron el mecanismo del hibridismo para construir prosopografías aterradoras, como es, en el caso de las sirenas, combinar elementos femeninos y aviares.

Puesto que, según García Gual (2014) no hay una teoría fundada que explique de forma fehaciente el paso de la representación de la sirena-ave a la sirena-pez, lo que tenemos es una profusión de fuentes clásicas y neohelénicas, que asimilan las sirenas a otros númenes y a sus respectivos atributos, ya sean ninfas, nereidas, oceánides, o como hijas de un dios-río como Aquelóo, o númenes concretos como Escila o Tritón. Lo importante, más allá de su prosopografía, es su función dentro del mito, y sin duda las sirenas son genius loci vinculadas a ciertos lugares sagrados de la costa, como cuevas o rocas que ya eran conocidas como entradas al Hades. De ahí su naturaleza oracular, como equivalente a los psicopompos clásicos en su guía de los difuntos por el ultramundo. Además, este ámbito o hábitat acuático es lo que explicaría este "deslizamiento" iconográfico: las mujeres-serpientes de las leyendas europeas de encantadas no son nunca aves, sino seres representados conforme a su naturaleza "anfibia", viven en cuevas o en la orilla de los ríos, por tanto, su representación pisciforme o asimilada a la serpiente, es la normal. 
Más allá del mito odiseico, es normal que hayan acabado siendo identificadas con las náyades o las nereidas, en suma, con damas de agua vinculadas bien a las costas (Maruxaina gallega) o bien a los cursos de agua dulce, y que se hayan ido también confundiendo sus atributos, de forma que las encantadas también destacan por el canto y la profecía. De esta forma, las sirenas se convierten a menudo en voces incorpóreas de las fuentes o manantiales, como las xanas, y tienen una naturaleza delicuescente, pues vienen a ser como un cuerpo o una neblina de agua que tiende a disolverse; es la definición que mejor cuadra a Melusina y a otras mujeres-serpientes, pues, a pesar de que se casen o de que tengan hijos, su inclinación natural es a hacerse líquidas.

Y aquí es donde se ratifica con toda lógica el cambio de la prosopografía de la sirena-ave a la sirena-pez, del espíritu tutelar y necromántico de aquella a la mujer con cola de pez, cercana a la iconografía de las nereidas, y unidas ambas representaciones por el nexo de lo hibrido. Incluso se producen confusiones entre las sirenas y las arpías, siendo así que el aspecto aviforme o pisciforme puede aparecer indistintamente en xanas (se dice por ejemplo que tienen patas de ganso), pero que cobran sentido si se cotejan con otros atributos, por ejemplo el largo cabello que cuelga.

Vicente García de Diego (1958) habló de un mecanismo que viene a cuento de estas interpenetraciones: la transpersonificación. En las leyendas, a menudo, hay a menudo un intercambio de personajes siempre y cuando desarrollen una función equivalente, por ejemplo, un gentil en las leyendas vascas, luego puede aparecer como un moro u otro antepasado. La razón se hace comprensible, pues, como decía Ana María Matute, los cuentos y las leyendas son vagabundos, "volanderos" (1999). De tal modo que el "trasiego" de gentes implica también "narrativas móviles" (Arapoglu, 2013), que ajustan etnotextos antiguos a versiones que pueden modernizar o permutar ciertos elementos.

\section{TIPOLOGÍA DE LA SIRENA}

Numerosos trabajos han examinado ya las fuentes literarias e iconográficas de las sirenas en la tradición occidental, de modo que sintetizaremos más bien los hallazgos de algunos de ellos para proponer criterios y modelos de intervención didáctica, que entendemos sería el principal foco de interés en nuestro ámbito.

Ibáñez (2014), apoyándose en las ideas de García Gual (2011), subraya que se produjo un auténtico cambio en el programa iconográfico de la tradición clásica al reemplazar la sirena-ave por la sirena-pez, de la mano de una cosmovisión que sustituía la naturaleza funeraria de la sirena homérica por una visión mucho más erotizada y delicuescente.

Siendo como es la sirena una variante más de las "damas de agua" que son auténticos universales del folklore, deberíamos tomar la palabra "delicuescente" en su sentido literal de "hacerse líquido", de absorber la humedad del ambiente y disolverse con ella, porque eso encaja, de un lado, con la representación de la sirena- 
ave, esto es, de su relación con el aire, con lo etéreo o vaporoso, y con la representación de la sirena-pez, a través de su relación con lo húmedo.

El canto y la presencia vaporosa son atributos explicables a través de su naturaleza de damas de agua. Primero, porque las náyades, las musas y otras deidades similares son ante todo oraculares, lanzan mensajes y profecías desde las fuentes, los pozos o los manantiales, e inspiran a los poetas, habitando en ellos. El canto y la luz son la forma corpórea en que se agita y se manifiesta el agua.

Aunque su origen, según las propias fuentes del mundo griego, son a menudo contradictorias y poco claras (Ibáñez, 2014, 52), sin duda la sirena-pájaro fue la forma más habitual, que llega hasta el Románico. La sirena-pez parte más bien del modelo de los cortejos o thiasos marino, donde aparecen las tritonisas.

Sin duda, la atribución de engaño de las sirenas proviene de un concepto griego, métis, que es aplicable más bien plenamente a su antagonista, a Ulises, quien en la tradición clásica es el polimétis, el "fértil en recursos". En realidad, que las náyades u otras damas de agua atraen a los hombres a sus "lugares encantados" y que éstos desaparecen en ellos, lo vemos en el mito de Hilas, el amigo de Hércules, que desaparece al ir a coger agua a una fuente. El supuesto rapto de las ninfas explica esta desaparición, que en este caso no se describe como fruto de engaño alguno. Del mismo modo, la asimilación de la sirena a la mujer lujuriosa no es más que otra relectura moralizadora de la sirena clásica, pues lo cierto es que la mujer-serpiente en el folklore no brilla tanto por sus dotes de seducción como por sus capacidades taumatúrgicas. Por ejemplo, Melusina es quien huye de su marido, y otro tanto ocurre en otras leyendas similares.

Se puede decir, pues, que en el transcurso de los siglos, las sirenas se aproximan cada vez más a la forma proteica de las ninfas, que en su gran variedad pueblan mares, ríos, cuevas, pozos y otros lugares encantados, y que comparten, pues, esa misma ambivalencia de las xanas asturianas, como númenes intermediadoras entre umbrales, $\mathrm{y}$, por ello mismo, vinculadas a la vida pero también a la vida, por lo que los valores antiguos oraculares se reactivan. En este sentido, el canto de las sirenas no es más que las voces del ultramundo que el chamán es capaz de evocar, y los otros atributos deben verse de una manera menos exotérica, pues el oro, los cabellos peinándose y otros detalles forman parte de las mismas hierofanías que por ejemplo relacionan el agua y la luz, es decir, subrayan su carácter visionario, su relación con los trances extáticos, como el que se dice que retuvo a Odiseo con Calipso en su cueva, rodeada de su cortejo de sirenas.

\section{LA SIRENA COMO PALIMPSESTO CULTURAL Y COMO DIALOGISMO. EL CASO DE LAS LAVANDERAS}

En este contexto, las múltiples representaciones de las sirenas son sin duda un ejemplo de "narrativas móviles" (Arapoglu, 2013), de discursos que han emigrado y se han metamorfoseado conforme al principio de A. M. Matute de que las narraciones tradicionales son "volanderas". Tan vagabundos como el mismo aedo, estos relatos 
han sufrido múltiples intercambios y trasvases, y han generado así múltiples identidades locales. Como el de dar un patrón local fundador a una ciudad, que es el caso de la sirena Parténope con Nápoles. O sea, un culto local sobre el presunto enterramiento de la sirena odiseica, que daría origen a la ciudad.

Otras veces la relación es con otras historias locales. La mujer serpiente, como la Tragantía de Cazorla, se generaba a partir de una historia de la Reconquista, con el emparedamiento de una princesa mora que acababa por mudar en el monstruo:

Yo soy la tragantía

hija del rey moro, quien me oiga cantar no verá la luz del día ni la noche de San Juan

Sin duda, esta mujer-serpiente está vinculada a la cultura del agua (Martos y Martos, 2013), y, por ende, a la iconología de las sirenas. Lo que interesa destacar ahora es que este aspecto terrorífico está relacionado, como en el caso citado de Calipso y Odiseo, con su carácter iniciático.

Es verdad que en épocas antiguas, en el medio rural, circulaban historias de ahogados que probablemente reforzaron a figuras como las lavanderas, que se acercaban a los chozos con alaridos desgarradores, buscando por las acequias a los hijos que decían habían perdido en alguna inundación. Y que, como las Banshee, vagabundeaban con un aspecto horrible, con voces cavernosas y golpeando el agua con las palas, con la letanía de ¡Aaaay mis hiiiijjjoooss... Vemos, pues, el rebrotar de la dimensión funeraria de la sirena antigua.

¿Eran mito o realidad estas lavanderas nocturnas (González y Fernández Vallés, 1969)? Si consultamos la mitología, es fácil encontrarse con figuras femeninas de aspecto monstruoso que se apostaban en los caminos y, decían, robaban niños, como los que ellas habían perdidos. Mujeres misteriosas que acostumbraban a peinar sus largas cabelleras con codiciados peines de oro, lamias con pies de ave o garras afiladas, según la imaginación de la gente, en historias que se podían contar de cualquier torrentera. Y había que mirarles los pies, y si los tenían de pato, pues había que echar a correr sin mirar atrás porque sin duda era una culebra que terminaría por comer vivo al viandante.

Todo ello venía a ser un ejemplo del hilo que une las tradiciones más antiguas con las leyendas locales más o menos modernizadas. También hay versiones que cuentan que estas lavanderas no vivían en el pueblo, que vivían en cuevas y que, cuando llegaba la hora del encantamiento, se las veía en su forma real de serpiente en su antro lleno de huesos -restos del festín de quienes asaltaban- y que tenían varias cabezas, tal como la Hidra de Hércules. Son, en definitiva, avatares de patrones conocidos, como la misma Serrana de la Vera y otras ogresas. 
Así pues, tales criaturas malignas y seductoras podrían ser como las lamias clásicas o las vampiresas actuales, aunque su aspecto monstruoso viene de lejos, está ya en representaciones mesopotámicas (Ibáñez, 2014). Pero lo cierto es que en ellas cabe reconocer las lúgubres historias de las feroces agoreras del folclore celta, las Banshee, que, con voz lúgubre y vestidas de túnicas amarillas, amonestaban a quien se atrevían a acercarse a las orillas de los ríos, las cavernas o las arboledas donde paraban. Incluso, en el folklore de Irlanda, alrededor de las batallas, si se las veía lavando la ropa ensangrentada de alguna persona, era signo premonitorio de su próxima muerte, tal era su capacidad de olisquear la muerte, de ser oráculos del sufrimiento o fantasmas de las lamentadoras clásicas.

A fin de cuentas, es similar a lo que en el folclore peninsular se contaba de las dueñas encantadas del Tajo o de las lamias vascas, de las xanas asturianas, de las donas d'aigua, de las mouras gallegas. Sólo en la Meseta había varios pueblos que se llaman "Fuentidueña", esto es, la dama de la fuente. No en vano Bécquer-como buen visionario- sabía mucho de sus peligros, y así lo plasmó en Ojos verdes y otras leyendas de mujeres fatales y jóvenes llevados por ellas al abismo. A propósito, la Banshee, que vaga por los árboles y las fuentes, es siempre más oída que vista.

A este respecto, llegados a este punto, cabe recordar una cita Erica Jong (1997) a propósito de las teorías de Robert Graves (1948) sobre la "Diosa Blanca", entendida como el arquetipo dinámica de la triple diosa, madre, hija y amante, o anciana, madre y doncella, conocida también con el nombre de Ísis por los egipcios, de Ishtar por los asirios, de Inanna por los sumerios y de Astarté por los fenicios, avatares todos para denominar a una imagen de la regeneración, mucho más cercano al carácter mediador de las sirenas, como seres que viven en el umbral de dos mundos.

Si la Diosa Madre es realmente todo eso, joven, doncella, anciana, entonces, ¿qué pasa con las sirenas, las ninfas, las arpías y todos estos espíritus femeninos a menudo malvados? En canciones y romances, éstos siempre tratan de apresar al hombre, de "engullirlo", y éste tiene que salir huyendo. La iconología de las sirenas sintetiza muy bien este aspecto monstruoso y femenino a la vez: mitad humana y mitad animal, con un rostro hermoso y el pelo largo y dorado. O sea que las lamias o las xanas que se peinan con un peine de oro en las fuentes y en los estanques, son realmente el anverso y el reverso de lo mismo. O como cuando se dice que algunas cambian sus hijos con los de las aldeanas, para que los amamanten, o si se cuenta que viven en cuevas y lugares apartados, como la Serrana de la vera, donde si son descubiertas, pueden causar grandes daños al curioso.

Dos caras de la misma moneda. Dan o quitan, pero en el fondo hay siempre como un trato y una posible recompensa. Este patrón implícito asoma hasta en las más modestas leyendas locales. Como la de la torca de Fuencaliente, en Soria, y de las historias que se contaban sobre esta sima de 25 metros de diámetros y 80 de caída libre En la torca se cuenta que perdió la vida Zaida (amante de Almanzor) a causa de los celos de éste; según se decía, los árabes que en ella se caían, aparecían vivos en 
África. Es decir, el pozo es siempre puente entre dos dimensiones, y la sirena es como el hierofante de este tránsito.

Los mitos nos hablan de forma reiterada de lo mismo: en estas aguas profundas, en las cuevas, en las simas emergen estas sirenas desde el fondo de los tiempos, cuando toman cuerpo los estados más alterados de nuestra conciencia, llevando a menudo a la desgracia; en todo caso, estos lugares encantados son un túnel que traslado al ultramundo, como esos desaparecidos que volvían luego a aparecer en otro sitio.

\section{ALGUNOS POSIBLES ITINERARIOS DIDÁCTICOS}

El recorrido de García Gual (2014) sobre el mito de la sirena pone de evidencia las diversas representaciones dialógicas (Bajtin, 1974), que vienen a constituir una suerte de constelación de atributos que orbitan sobre esta figura aunque a veces sean más bien contradictorios. La sirena homérica se parece más bien a un genio alado (Alganza, 2012), y poco tiene que ver con la imagen sofisticada y erotizada de la sirena postclásica, asimilada prácticamente a la mujer fatal del romanticismo. En realidad, la ninfa que peina sus cabellos con un peine de oro a la orilla de una rivera, remite en realidad a otros motivos folclóricos más simples que vemos en las leyendas europeas, por más los pintores prerrafaelistas o los poetas del Modernismo saquen partido a esta actitud en apariencia indolente. Las ninfas están "atadas" a las riberas o a las cuevas como las sirenas estaban "encadenadas" a las rocas, por su naturaleza de "genius loci" y no por una postura sedente o de otro tipo.

De modo que, con la misma legitimidad, vemos representaciones antiguas que aproximan prácticamente la imagen de la sirena a la de "vampiro" (Alganza, 2012) y otras que usan una delicada representación hiperestésica y sensual, hasta llegar a figuraciones que inciden en un mundo claramente sexualizado, como en la novela Sirena Selena vestida de pena de Mayra Santos-Febres (Rivera, 2008).

Por consiguiente, visibilizar todo este "itinerario" de representaciones es por sí mismo un enfoque de gran interés para la educación literaria, en la medida en que se establece un diálogo no solo dentro de la propia tradición literaria, sino entre éstas y sus referentes en el folclore, pero también en la cultura mediática y digital, pues la sirena se ha convertido en una especie de marca o "branding" que subyace a multitud de prácticas, empresas y productos, desde cosméticos o muñecas a Starbucks.

La propia diversidad iconográfica, que pasa por la sirena-pájaro, la sirena-pez, la sirena de cola bífida y otras, nos evidencia este dialogismo (Bajtin, 1974) o cruces de tradiciones, a veces disonantes, pues las sirenas que cantan o danzan alegremente actúan como ninfas, mientras que las que guardan, vigilan, acechan o protegen, son más bien como las damas de agua que custodian un lugar encantado o un tesoro, y cuya relación con los eventuales visitantes es siempre ambigua e inquietante, tal como apreciamos en el mito de Hilas, de quien se dice simplemente que desapareció cuando fue a coger agua a una fuente. 
Otra forma de revisión, deconstrucción o subversión de estas representaciones folklóricas, literarias y artísticas de las sirenas, pasa desde la óptica feminista por reivindicar el empoderamiento de la mujer (Beteta, 2014). Proponen convertir estas representaciones de la imagen de la mujer, a menudo malévolas, en nuevos iconos de feminidad, mucho más polifónicos, "desmontando" así la ideología patriarcalista tendente a convertir en monstruos a las mujeres (Medusa, Lamias, etc.). Por ejemplo, la iconografía prerrafaelista de las sirenas (v.gr. Sirena de Waterhouse) está impregnada de romanticismo, pero también de un estilismo donde la luz y lo acuático prevalecen sobre las figuras de lo masculino (por ejemplo, las pinturas de la Sirena y el pescador de Frederic Leighton o de Knut Ekwall).

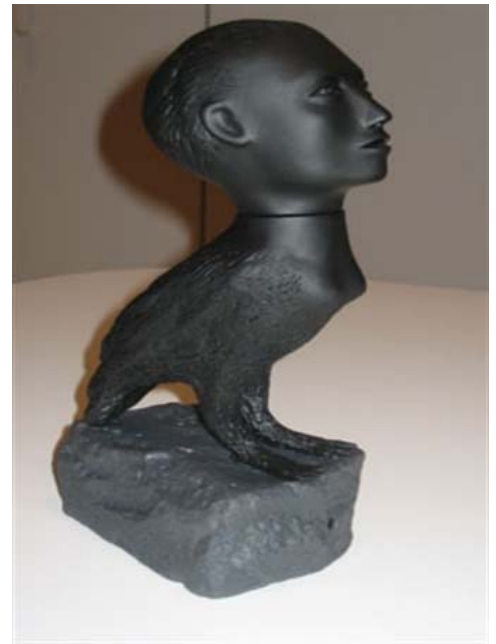

Singing Siren, Kiki Smith

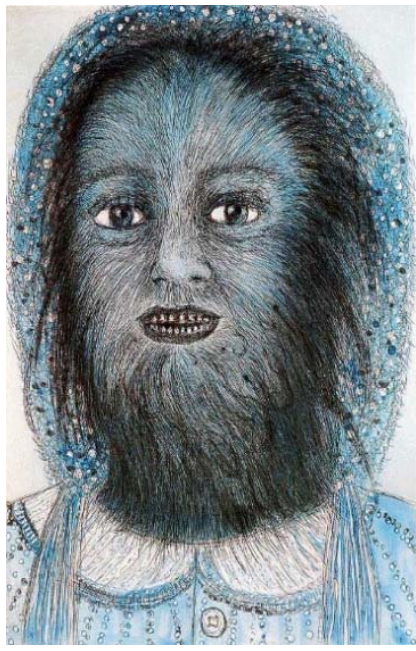

Wolf Girl (1999), Kiki Smith

Por otra parte, artistas contemporáneas han fusionado estas tradiciones con sátira, ironía o humor, es el caso de Kiki Smith (Bradley, 1996) en su relectura o reinterpretación de las arpías y las sirenas. De tal modo que la iconografía de las sirenas se deconstruye para convertirse en justo lo que sus censores pretendían evitar: fisonomías delicuescentes porque precisamente se parecen a la figura de las leyendas tradicionales -madre del agua, damas de agua, lavanderas-, jabones, dobladas, arremangadas, en poses que no son precisamente ni amenazantes ni indolentes.

De forma paralela, las investigaciones de la arqueóloga M. Gimbutas (Mega, 2013) han puesto en valor las actividades de la agricultura, la cestería, la cerámica o el hilado como partes de la inteligencia práctica, de la habilidad de la mujer y de la cultura de la "Vieja Europa", valores que se encarnan en una figura como la Penélope homérica, capaz de gobernar su casa y engañar a los pretendientes. Las damas de agua son transgresoras no solo por su desnudez sino por todo lo que hacen, cantan, danzan, o proponen alguna clase de "juego", como las encantadas. 
La demonización patriarcal de estas figuras es la misma que afecta a brujas, lamias, vampiras, etc. como encarnaciones del mal y de la lascivia, y que vemos que se prolonga en recreaciones modernas, como el Drácula de Coppola, con sus vampiras, que son siervas lujuriosas del diablo (Beteta, 2014), con una sexualidad excesiva, ausencia de instinto maternal, nocturnidad...Esta imagen perversa es lo primero que es preciso revertir.

A este respecto, Beteta afirma:

En este proceso de deconstrucción de los discursos patriarcales, algunas artistas denuncian la deslegitimación que han padecido y padecen las mujeres apropiándose precisamente de las representaciones «monstruosas» de la naturaleza femenina para convertirlas en «iconos feministas». Son artistas que han dado forma a un nuevo feminismo visual basado en el concepto de subversión, es decir, toman los modelos clásicos de deslegitimación femenina para deconstruirlos y convertirlos en iconos del feminismo (Deepwell, 1998). La iconografía de las brujas, amazonas, vampiras, sirenas, arpías, esfinges, etc., se deconstruye y subvierte para convertirla en el paradigma de aquello que sus creadores pretendían combatir $(2014,296)$.

Por tanto, es una inversión de los conceptos de monstruosidad y de pecado tal como aparecían ligados a las sirenas en la tradición (pos)medieval, usando en este caso las aportaciones plásticas de artistas como Cindy Shermann, Kiki Smith, Leonora Carrington, Dorothea Tanning, Paula Rego, Remedios Varo o Unica Zürn (Beteta, 2014). Al recuperar el mito primigenio en toda su capacidad dialógica, por ejemplo, la bruja primigenia que encarna Hécate, Circe, Medea o las Moiras, enfatizamos el valor de la transmisión generacional femenina de los conocimientos que constituyeron la "hechicería antigua" (Caro Baroja, 1961), deslegitimada de forma sesgada como culto al diablo, y luego objeto de la persecución conocida como caza de brujas. En cambio, se omiten a menudo la dimensión más moderna de estas figuras en relaciones a saberes ancestrales, por ejemplo, su relación con las plantas y pócimas, sus oficios de partera, matrona o curandera, frente a los saberes institucionales.

Frente a esta arquetipo de la bruja satánica, una lectura feminista y ecocrítica debe poner en valor los aspectos positivos y alejar la imagen "castradora" de esta personificación de la mujer, que ya aparece en las figuras de Circe o Calipso, que tratan de engañar o paralizar al hombre, y que se reinventa en el tópico de la "femme fatale". Como en esta reinvención de Kiki Smith de la "doncella salvaje", una mujerlobo o mujer barbuda.

Mujeres en la Hoguera (2001) es otra representación suya con gran fuerza visual. Son figuras humanizadas, lejos del histerismo o la culpabilidad, que sirven, pues, para el empoderamiento de las mujeres, precisamente en un contexto de frivolización de toda esta temática. "Escuelas de Sirenas" (1994) es un ejemplo de uso de coreografías acuáticas para transmitir los mismos arquetipos de siempre. 
La ecocrítica, al poner el foco de atención en la naturaleza como leit-motiv, y el ecofeminismo, al releer tradiciones como la de las sirenas desde otras ópticas, posibilitan crear otros itinerarios y otras metodologías de lectura, que se sostendrían en una forma de deconstruir, de montar y de des-montar los relatos arquetípicos que conocemos, a fin de que

A través de la creación de personajes y de la alteración de su representación se puede relatar la subjetividad de los individuos a modo de narración empática; es decir, como el recurso que cada persona para explorar el mundo y construir una interpretación personal a partir de los fragmentos de su memoria particular y su vínculo con el devenir histórico universal. Una reconstrucción de la memoria que reescriba la Historia incorporando a las mujeres como sujetos activos, creadores y empoderados; mujeres sin cadenas (Beteta, 2014, 306).

Constatamos, pues, que la lectura deconstructiva de Derrida (2001) se ha aplicado de forma sistemática por parte de la crítica feminista (1989), a obras como Cien años de soledad o La casa de los espíritus. Con todo, parece especialmente útil si queremos "revisitar" mitos y tradiciones transculturales, como éstas.

Incluso más allá de visibilizar y reivindicar a la mujer, la revisión que proponemos se acerca también a una lectura "espiritualista", en el sentido de no ceñirse a la materialidad o literalidad de los signos o atributos. Es el caso de la sirena-pez o de cola-bífida, cuya interpretación es siempre objeto de polémicas. Lo importante es que el contacto con la sirena es una ventana que conecta con el ultramundo, y en esa medida, se puede hacer una relectura "neopagana" (Brenis, 2002) de estos mitos, por ejemplo, poniendo en valor lo que hace Calipso con Ulises en su "cueva o antro iniciático", que no es otra cosa que una iniciación a través de un trance extático inducido en la cueva. Saberes en suma mistéricos, propios de un chamán, con lo cual entramos en el patrón de la maga. En realidad, gran parte de la cultura popular moderna, como en el caso de Star Wars y otros éxitos, se apoyan en esta revisión de mito bien al modo de la New Age o bien fundada en estudios como la arqueomitología de Gimbutas (Mega, 2013).

En efecto, los chamanes, en efecto, dominaban algunas técnicas que creo son significativas para el tema de las sirenas, y que vemos en el episodio comentado de Calipso y Odiseo. Por ejemplo, elementos para inducir los estados alterados de conciencia: técnicas que facilitan el trance extático, plantas, bebidas, lugares o momento, como partes de un todo en que el mago era capaz de abrir su mente al máximo. También, la música, los cantos o las palabras sagradas como accesos al ultramundo, o el vuelo del alma a otro mundo, el acceso a mundos invisibles con ayuda de los ancestros, el guía, etc., o bien, en el reverso, la visita de seres espirituales a nuestro plano existencial. Esto tendría que ver con la forma primitiva de sirena como ave, pues mediante la magia animal, es decir, la capacidad de identificarse y metamorfosearse en un animal, en realidad se está indicando la importancia del renacimiento o regeneración de uno mismo. 


\section{GUÍA DE LECTURA INTERTEXTUAL A PARTIR DE LAS LEYENDAS DE LA SIRENA PARTÉNOPE Y DE "OJOS VERDES" DE BÉCQUER}

Todos los planteamientos teórico-prácticos comentados deben ser instrumentados en proyectos de intervención. A modo de muestra, vamos a desarrollar uno que consistiría en una lectura intertextual y comparativa, a partir de dos textos, pensado para $3^{\circ} / 4^{\circ}$ de la ESO, dentro de los programas vigentes de Lengua y Literatura. A efectos de definir esta propuesta, no vamos a abundar en la controversia que origina la lectura deconstructiva (Derrida, 2001) u otras cuestiones hermenéuticas; baste reconocer que un texto puede ser leído de muchas maneras, y que la deconstrucción debe usarse ante todo como una estrategia que, en el caso de la educación literaria, pone en valor el potencial de sentido de un texto y a la vez cuestiona los sentidos unívocos y los estereotipos, al armar y desarmar las "piezas" del texto.

Así, con solo dos textos a comparar, la leyenda tradicional napolitana de la sirena Parténope (Serao, 1891), y el texto de Bécquer "Ojos verdes", podemos cotejar los itinerarios antes glosados, desde la leyenda odiseica de la que se desgaja la historia de Parténope hasta la literaturización que opera el texto becqueriano sobre los hipotextos folclóricos de damas de agua (Martos y Martos, 2014). Sin duda, la dama becqueriana no es tampoco una simple náyade de una fuente sino más bien como una mujer seductora que atrae a Fernando con su voz melodiosa, como las sirenas. Los textos dibujan, pues, un círculo que explica la evolución desde la figura de sirena homérica, vinculado a lo funerario, a la sirena sensual y erotizada de la tradición artística occidental (Ibáñez, 2014), por lo que podríamos trazar la siguiente guía didáctica para el profesor:

\section{Actividades de Presentación y Motivación (antes de la lectura)}

La relación entre la creación literaria y la memoria cultural (folclore) serían la prelectura o ambientación para presentar tanto la leyenda napolitana como la de Bécquer, la cual recrea libremente la tradición folclórico-literaria de las damas de lago $\mathrm{y}$ ondinas que protagonizan numerosos textos europeos. La leyenda napolitana ya vincula la sirena con la muerte, de hecho, se relaciona el Templo de las Sirenas con una "boca del infierno", y es el sepulcro de Parténope lo que da origen a la ciudad, si bien ésta no se representa ya como la sirena-pájaro sino como la sirena-pez.

Práctica Controlada (durante la lectura)

Actividad Modelo

1. Proponer una lectura comprensiva supone ir aislando los diversos cuadros en que Bécquer monta la leyenda. Antes que nada, Bécquer coloca una especie de prólogo en que subraya el motivo de los ojos verdes como inspiración de la leyenda e invoca la complicidad de los lectores para hacerse entender. En la leyenda napolitana, la justificación es explicar el origen de la ciudad a partir de la historia de la sirena. A diferencia de la concisión de la leyenda italiana, el cuadro II en Bécquer conlleva una elipsis narrativa en que Fernando e Íñigo conversan sobre la fuente y la dama de agua que la habita, narrando Fernando que ya ha ido al lugar y le ha parecido verla. Las 
advertencias de Iñigo y la sentencia Cúmplase la voluntad del cielo son premonitorias de un final. El cuadro III, el del encuentro, empieza nuevamente por una elipsis narrativa y un diálogo entre Fernando y la ondina.

2. El esquema temático propio de una lectura analítica (la secuencia de la atracción fatal) focaliza el encuentro, precedido de una primera experiencia con la Naturaleza (la cacería) y de una indagación previa de Fernando que tiene una doble finalidad: demorar el desenlace y a la vez explicárnoslo, ya que él está dispuesto a darlo todo por una sola mirada de esos ojos. A diferencia de la leyenda tradicional, Fernando es advertido del poder de la ondina y busca, digamos, su perdición, que para él es más bien una redención. Fernando se coloca así en un nivel superior, pues desprecia los temores como simple superstición. Cuando ella le responde que tal vez sea un demonio, su respuesta es la misma.

3. Así pues, ahora es cuando cobran sentido las descripciones y los diálogos que jalonan las escenas: lo que Fernando persigue es algo inasible, simbolizado en esos ojos verdes. Así pues, los códigos literarios y folclóricos se superponen, desde la ambientación medievalistas o el amor exaltado a la "mujer fatal" en que se transmuta el genio femenino del lago.

4. Establecer otros hitos intertextuales. Por ejemplo, comparar estas leyendas con La sirenita de H.C. Andersen, publicada en 1835, donde la melancolía por un cuerpo y un alma humana parece ser el sentimiento central.

Práctica independiente (después de la lectura)

\section{Actividades de Grupo}

1. Indagar las fuentes folclóricas de esta leyenda: xanas en Asturias, lamias en el País Vasco, dones de agua en Cataluña... y, en general, ninfas, melusinas y doncellas de mar, mujer-cisne, etc., estudiando la asimilación de las sirenas a estas distintas prosopografías y sus ambivalencias

2. Contrastar posibles fuentes literarias de esta leyenda que más pudiera conocer Bécquer, desde las sirenas que atraen a los marinos en la Odisea hasta las baladas de Heine sobre Lorelei. En España, se debe cotejar particularmente con La ondina del lago azul, de la escritora cubana Gertrudis Gómez de Avellaneda y La fuente de la mora encantada de Manuel José Quintana.

3. Debatir la representación de lo exótico en las distintas tradiciones. Bécquer focaliza el elemento de los ojos (dibujaba a menudo siluetas de la Ofelia shakespereana y su mujer ideal es sin duda germánica), en cambio en la leyenda napolitana el canto es el elemento más destacado.

\section{Actividades individuales}

1. Explíquese en qué sentido Bécquer hace un uso teatral del diálogo.

2. ¿El paisaje es un simple telón de fondo o se relaciona "empáticamente" con los sentimientos de los personajes?, ¿puede hablarse de un alma del paisaje en la leyenda de Bécquer?

3. Analizar algunos recursos retóricos empleados por Bécquer.

4. Los mitos clásicos (Narciso, Hilas, Hermafrodito...) suelen acabar con la idea de que el hombre sucumbe en el agua por obra de una ninfa, náyade, sirena u otro ser 
mitológico. Recrea una versión de alguna de estas leyendas con un final distinto, aplicando técnicas de Rodari.

\section{Apoyo y Recuperación}

1. Para entender los materia/es con que Bécquer compone la leyenda, podemos detenernos en elementos concretos, como la descripción de la fuente en la escena II. Fernando, aquejado ya de un "mal", le describe a su amigo cómo es ese lugar paradisíaco en términos que no desmerecen los de la tradición clásica del locus amenus; sin embargo, en seguida aparecen connotaciones románticas: la soledad, rumores desconocidos, una inefable melancolía, y, de forma presentida, los invisibles espíritus de la naturaleza que se reconocen en el inmortal espíritu del hombre.

2. Se entiende, pues, que Bécquer haya distorsionado una historia tradicional de miedo o amenaza hacia el hombre para transformarlo en una leyenda de anhelo del absoluto, del amor. Los verbos dubitativos (creí haber visto, parece...) insisten en ese juego entre ilusión y verdad, propio de la imaginación romántica.

\section{Trabajo en Equipo}

Esta leyenda se publicó en diciembre de 1861. Unos meses después apareció El rayo de luna. ¿Se puede creer en una influencia directa, en cuanto a los temas y la técnica, de Los ojos verdes. Id anotando en columnas los parecidos y diferencias entre una y otra.

\section{Ampliación}

El tema de las sirenas o ninfas que atraen a los hombres y lo destruyen ha pasado a diversas óperas, como las realizadas sobre el tema de Lorelei, y otro tanto cabe decir de la pintura del s.XIX, no sólo la romántica sino la posterior de temas simbolistas. Relaciónense obras musicales y pictóricas -incluyendo los grabados, como los de Doré- con estos temas legendarios.

En realidad, esta aproximación didáctica planteada pretende que el alumno compare los códigos de las leyendas tradicionales con los códigos que subrayen a la representación o imagen de la mujer en el conjunto de la tradición literaria (véase mapa de conceptos adjunto), a fin de que, en sucesivas aproximaciones, se puedan establecer conexiones de mayor calado. Por ejemplo, la distinción entre el amor cortés vs. el amor romántico no es pertinente en estas dos leyendas, pero sí la idea folclórica del amor como principio vital, pues estas damas de agua son, a fin de cuentas, una variante de la magia amorosa que describe Caro Baroja (1961) a propósito de La Celestina y de las brujas medievales en general.

Vemos, pues, que una lectura intertextual y deconstructiva sirve para contrastar estereotipos y reconocer los códigos folclóricos y/o literarios, así como las maneras en que éstos interactúan y se "sobre-escriben", dando lugar a auténticos palimpsestos culturales (Genette, 1982). Todo ello, pensamos, hará emerger nuevas sensibilidades acerca de la imagen de la mujer, generados precisamente desde la educación literaria. 
En última instancia, la demonización o erotización de la sirena serían los polos complementarios de una mentalidad patriarcalista (Figes, 1972), que va cambiando o distorsionando el sentido originario de muchos de los elementos originarios, provocando lo que Graves (1948) llama "iconotropismos", a la hora de describir las transformaciones de los mitos en torno a lo que él llama la "Diosa Blanca".

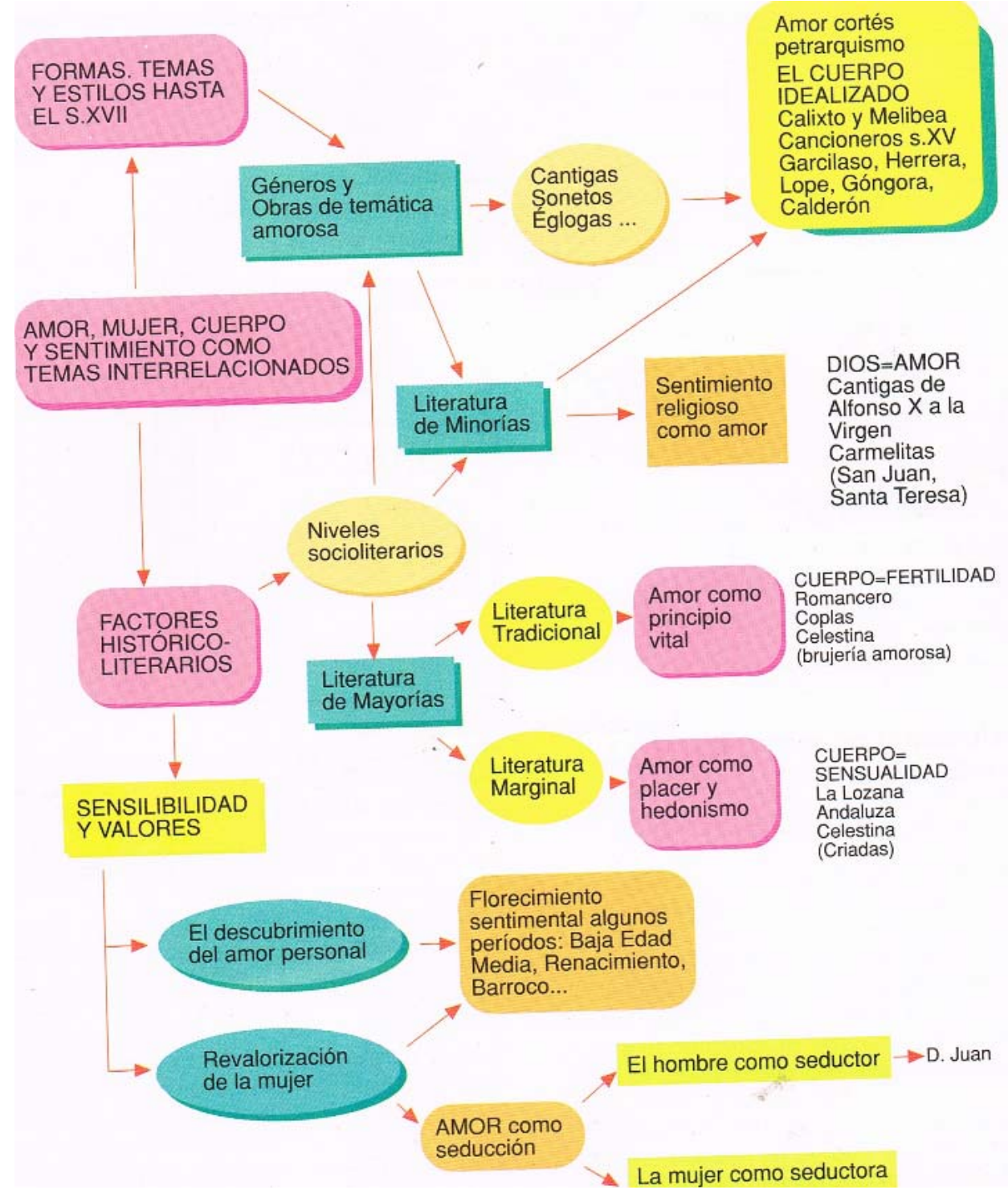




\section{CONCLUSIONES}

Los cambios culturales glosados nos han llevado a una transformación física del estereotipo de las Sirenas desde la mujer-ave de la cultura grecorromana a la mujerpez de la tradición medieval, al igual que la interpretación erótica de las Sirenas ha terminado por reemplazar a la simbología funeraria original (García Gual, 2011). Es sabido que las sirenas primigenias griegas están fijas a las rocas y tienen un carácter funerario, y a partir de esta tradición odiseica es cuando constatamos una sucesiva ramificación de iconologías.

En cualquier caso, el cristianismo no conservó la parte positiva que la sirena tenía en la cultura griega (García Álvarez, 2003) como conductora de almas, y se empeñó en relacionarlas con la tentación, la lujuria y el pecado.

Ello nos posibilita unos itinerarios de lectura susceptibles de utilizar algunos mecanismo de la deconstrucción (Derrida, 2001), en tanto que se trata de combatir ciertos estereotipos.

El ecofeminismo (Puleo, 2011) reivindica una interpretación renovada de las mujeres tildadas de brujas, herejes o visionarias ("lunáticas" como mujeres libres y sabias, al modo de los chamanes. Mujeres salvajes, sin domesticar, en conexión con la tierra y los ciclos naturales, que se contraponen a las imágenes "patriarcalistas" de ogresas, histéricas, vampiras o muñecas (Pedraza, 1996).

En esta línea, los manantiales, las fuentes, las pozas son como bocas por las que Gaia, al decir de los nuevos místicos, lanza sus humores. No sabemos muy bien por qué un acantilado, un barranco, una cueva o una fuente son focos de esta sacralidad antigua y renovada, pero la presencia de las sirenas y otros númenes nos lo señalizan.

Lo cierto es que el agua es siempre limes del más allá, y que ciertos cursos de agua y lugares húmedos son lugares de revelación, de aparición, de hierofanía, en el sentido doble de la raíz indoeuropeo de "fanía", algo que aparece y algo que brilla o refulge. De modo que, en relación a las criaturas como las sirenas de las leyendas, es sabido desde la Odisea que no había que fiarse de su aspecto o de su canto, igual que las encantadas podían revelarse en realidad como mozas con patas de ganso.

En resumidas cuentas, las múltiples representaciones de sirenas son un ejemplo de "narrativas móviles" (Arapoglu, 2013), en tanto que han surgido de influencias intertextuales e interdiscursivas, en forma a menudo de influencias, préstamos o transculturaciones de todo tipo. Por tanto, la tradición de sirena se configuraría como un palimpsesto de identidades (Genette, 1982), susceptibles de ser aprovechadas para la educación literaria de los alumnos en alguna de las maneras que hemos sugerido en páginas anteriores.

\section{BIBLIOGRAFÍA}

ALGANZA RoldÁN, Minerva (2012): "Genios alados, monstruos y mujeres fatales en la mitología griega", en Vampiros a contraluz: constantes y modalizaciones del vampiro en el arte y la cultura, Granada, Comares, 1-18. 
AMAYA, Lyana María y A.M. FERNÁNDEZ (1989): "La deconstrucción y la crítica feminista: Lecturas posibles de Cien años de soledad y La casa de los espíritus", en Nuevo texto crítico, 2(2), 189-195.

ARAPOGLOU, Eleftheria, M. FODOR y J. NYMAN (2013): Mobile narratives: travel, migration, and transculturation, Oxford, Routledge.

BAJTIN, Mijail (1974): La cultura popular en la Edad Media y el Renacimiento. El contexto de François Rabelais, Barcelona, Barral Editores.

BETETA MARTín, Yolanda (2014): "La sexualidad de las brujas. La deconstrucción y subversión de las representaciones artísticas de la brujería, la perversidad y la castración femenina en el arte feminista del siglo XX", en Dossiers Feministes, 18, 293-307.

BRADLEY, Jessica (1996): "Kiki Smith", en Les Cahiers du GRIF, 1(1), 63-69.

BRENIS, Elizabeth Díaz (2002): "Nueva Era: una religión para la polis posmoderna", en Antropología. Boletín Oficial del INAH, 68, 44-49.

CARo BARoja, Julio (1961). Las brujas y su mundo, Madrid, Alianza, edición de 2003.

DERRIDA, Jacques (2001): La deconstrucción en las fronteras de la filosofía: La retirada de la metáfora, Barcelona, Universitat Autònoma de Barcelona.

FigeS, Eva y C. MARTín GAITE (1972): Actitudes patriarcales: las mujeres en la sociedad, Madrid, Alianza.

FouRGOUS, Denise (1993). L'hybride et le mixte. Mètis. Anthropologie des mondes grecs anciens, 8(1-2), 231-246.

GALEANO, Eduardo (1982): Memoria del fuego/Vol I. Los nacimientos, Madrid, Siglo XXI.

García Álvarez, Carlos (2003): El laberinto del alma. Una interpretación de las enjutas de las capillas absidales de la catedral de León, 170, León, Universidad de León.

GARCÍA DE DIEGO, Vicente (1958): Antología de leyendas de la literatura universal (Vol. 1), Barcelona, Labor.

GARCía GuAL, Carlos (2011): "Metamorfosis de las sirenas", en Filosofía, Hermenéutica y Cultura: Homenaje a Andrés Ortiz-Osés (167-196), Deusto, Universidad de Deusto.

GARCía GUAL, Carlos (2014): Sirenas. Seducciones y metamorfosis, Madrid, Turner Noema.

GENETTE, Gerard (1982): Palimpsests: Literature in the Second Degree. Ed. de 1997. Trans. Channa Newman y Claude Doubinsky, Lincoln, University of Nebraska Press.

GLISSANT, Edouard (1995): Introduction à une poétique du divers. Montréal, Presses de l'Université de Montréal.

GonZÁlez SERrano, Pilar y M. Aguirre CASTRO (1997): "Espíritus malignos, dragones y lamias", en Más cerca de Grecia, 12, 213-224. 
GONZÁLEZ Y FeRnÁNDEZ VALlÉS, José Manuel (1969): "Sucedidos míticocristianos. Etnografía y folklore de una parroquia asturiana Santa Olalla de Valduno)", en Revista de Dialectología y Tradiciones Populares, 25(1), 107-128. GRAVES, Robert (1948): La diosa blanca: gramática histórica del mito poético, Madrid, Alianza, edición de 1986.

IBÁÑEZ CHACÓN, Alvaro (2014): "La metamorfosis de las Sirenas: a propósito de un libro reciente", en Thamyris, nova series: Revista de Didáctica de Cultura Clásica, Griego y Latín, 5, 157-167.

JONG, Erica (1997): Witches, New York, Harry N. Abrams Incorporated.

LOTMAN, Yuri (1979): Semiótica de la cultura, Madrid, Cátedra.

MARTOS GARCÍA, Alberto y E. MARTOS NÜÑEZ (2014): "Ojos verdes: imaginarios femeninos y narrativas transtextuales", en Acta literaria, 49, 123-138.

MARTOS NúÑEZ, Eloy y A. MARTOS GARCÍA (2013): "Imaginarios del devoramiento en la cultura del agua: dragones," tragantía", tragaldabas y otros espantos", en Indivisa: Boletín de estudios e investigación, 13, 122-143.

Mega, Jaime Orestes, L. Oliveira Matos y A. C. Ribeiro (2013): "Arqueomitologia: uma breve introdução", en Tessituras: Revista de Antropologia e Arqueologia, 1(1), 101-108.

MiLloneS, Luis y H. Tomoeda (2011): "Las sirenas de Sarhua", en Letras, 75, 107/108, 15-31.

PEDRAZA, María del Pilar (1996): "Las últimas ogresas: histéricas, vampiras y muñecas", en Historia del arte y mujeres, 153-174. Málaga, Servicio de Publicaciones de la UMA.

PEDROSA, José Manuel (2015): "Las sirenas, o la inmortalidad de un mito (una visión comparatista)", Revista Murciana de Antropología, 22, 239-300.

PUleO, Alicia H. (2011): Ecofeminismo para otro mundo posible, Madrid, Cátedra.

RIVERA, Ángel (2008): "Sirena Selena vestida de pena de Mayra Santos-Febres: Consumidora y consumida, la nueva ciudadana del Caribe", en Bulletin of Hispanic Studies, 85(1), 97-110.

RODRíGUEZ LOPEZ, María Isabel (1998): "Las sirenas: génesis y evolución de su iconografía medieval, en Revista de arqueología, 211, 42-51.

Rodríguez LóPEZ, María Victoria y F. PÉREZ SUESCUN (1997): "Las sirenas medievales: aproximación literaria e iconográfica", en Anales de historia del arte, 7, 55-66. Departamento de Historia del Arte.

RODRíGUEZ PEINADO, Laura (2009): "Las sirenas", en Revista digital de iconografía medieval, 1(1), 51-63.

SATRÚSTEgUi, José María (1999): "Lamias y sirenas a través de la simbología", Cuadernos de etnología y etnografía de Navarra, 31(74), 497-520.

SERAO, Matilde (1891): Leggende napoletane, Modena, E. Sarasino. 